Çukurova Üniversitesi Mühendislik Mimarlık Fakültesi Dergisi, 35(3), ss. 729-736, Eylül 2020

\title{
Toz Enjeksiyon Kalıplama ile Üretilen Parçada İç Vida Geometrisinin Elde Edilmesinin Araştırılması
}

\author{
Mehmet SUBAŞI" ${ }^{* 1}$ \\ ${ }^{1}$ Gazi Üniversitesi, Teknik Bilimler Meslek Yüksek Okulu, Makine ve Metal Teknolojileri \\ Bölümü, Ankara
}

$\ddot{\mathbf{O z}}$

Geliş tarihi: 16.09.2020 Kabul tarihi: 23.10.2020

Toz enjeksiyon kalıplama (TEK), metal ve seramik tozlarından hassas geometrili parçaların üretimi için kullanılan ideal bir tekniktir. TEK yönteminde parçanın iç kısmında vida geometrisi elde etmek için hareketli maça sistemine ihtiyaç vardır. Fakat bu sistemin yapılması hem zor hem de zaman alıcıdır. Bu çalışmada iç vida geometrisi, parça içerisindeki insört ile elde edilmeye çalışılmıştır. Bunun için, 316L paslanmaz çelik besleme stoku kalıp içerisine enjekte edilerek parça üretilmiş sonrasında uygun matkapla delik delinmiş ve M4 vida çekilmiştir. Parça içerisine konulacak vida geometrili insörtler yüksek sıcaklığa dayanıklı hegzagonal bor nitrür ve krom ile kaplanmıștır. Böylece besleme stoku bölgesindeki vida geometrisinin insört ile difüzyonunun engellenmesi amaçlanmıştır. Hazırlanan numuneler iki farklı sinterleme sıcaklığı $\left(1260{ }^{\circ} \mathrm{C}-1340{ }^{\circ} \mathrm{C}\right)$ ve süresin de (30-90 dakika) sinterlenmiş̧tir. Çalışma da insört üzerine uygulanan ara katmanların vida geometrisine etkisi araştırılmıştır. Deneyler sonucunda vidalı insört üzerindeki hegzagonal bor nitrür ve krom ara katmanlarının difüzyonu engellemediği belirlenmiştir.

Anahtar Kelimeler: Toz enjeksiyon kalıplama, Vida geometrisi, Ara katman, Krom, Hegzagonal bor nitrür, Sinterleme, $316 \mathrm{~L}$ besleme stoku

\section{Investigation of Achieving Internal Screw Geometry in Part Produced by Powder Injection Molding}

\begin{abstract}
Powder injection molding (PIM) is an ideal technique for the production of precision geometry parts from metal and ceramic powders. In PIM method, a moving core system is needed to obtain screw geometry inside the part. However, making this system is both difficult and time-consuming. In this study, the internal screw geometry in the part has been tried to be obtained with the insert. For this, the part was produced by injecting 316L stainless steel feedstock into the mold, then a hole was drilled with a suitable drill and the M4 screw was pulled. Screw geometry inserts to be placed in the part are coated with hexagonal boron nitride and chrome resistant to high temperature. Thus, it is aimed to prevent the diffusion of the screw geometry in the feedstock area with the insert. The samples prepared were sintered
\end{abstract}

*Sorumlu yazar (Corresponding author): Mehmet SUBAȘI, msubasi@ gazi.edu.tr 
at two different sintering temperatures $\left(1260{ }^{\circ} \mathrm{C}-1340{ }^{\circ} \mathrm{C}\right)$ and time $(30-90$ minutes $)$. In the study, the effect of intermediate layers applied on the insert on screw geometry was investigated. As a result of the experiments, it was determined that hexagonal boron nitride and chromium interlayers on the screwed insert did not prevent diffusion.

Keywords: Powder injection molding, Screw geometry, Interlayer, Chrome, Hexagonal boron nitride, Sintering, $316 \mathrm{~L}$ feedstock

\section{GIiRiş}

Toz enjeksiyon kalıplama (TEK) da ilk olarak metal ve seramik tozları bağlayıcı bir sistem ile karıştırılarak besleme stoku hazırlanır. Hazırlanan besleme stoku kalıp boşluğuna enjeksiyon yapılarak ham parçalar elde edilir. Kalıptan çıkan ham parçalar kimyasal ve 1sıl olmak üzere iki aşamalı bağlayıcı giderme işlemine tabi tutulurlar. Bağlayıcı giderme aşamasından sonra parçalar besleme stokunun özelliğine bağlı olarak atmosfer kontrollü ortamda veya hem atmosfer kontrollü hem de vakum ortamında sinterleme işlemine tabi tutulurlar. Sinterleme işleminden sonra parçada nihai yoğunluk ve şekil elde edilir.

TEK yönteminin prensipleri plastik enjeksiyon kalıplama tekniğine dayandığı için parça üzerindeki girintiler için erkek, çıkıntılar için dişi maçalar kullanılması gereklidir. Eğer parça üzerinde kalıbın açılma yüzeyinden farklı bir düzlemde geometri elde edilmesi gerekiyor ise hareketli bir maça sistemine ihtiyaç duyulmaktadır. TEK yöntemi ile içi vida geometrisine sahip bir parçayı elde etmek için hareketli bir maça sistemi gereklidir.

Bir parçanın, silindirik iç veya dış yüzeyleri üzerine açılan helisel girinti ve çıkıntılara vida denir. Delik içerisine vida geometrisi oluşturma işleminde farklı zorluklar olmasına rağmen tasarımlarda yaygın bir şekilde tercih edilmektedir. Bir makine sistemini oluşturan elemanlar hangi yöntem ile üretilir ise üretilsin sistemin ortaya çıkması için montaj edilmeleri gerekmektedir. Parçaların montajında da kullanılan en yaygın yöntem cıvata ve somun bağlantı şeklidir. Bu yöntem kullanılarak birleştirilen sistemlerin hedeflenen bağlantı kalitesinde olması da vida geometrisinin, yüzeyinin toleranslar içinde olmasını gerektirir [1,2].
Literatürde bir parçanın ya da içerisindeki vida geometrisinin talaşlı imalat ile elde edilmesine yönelik birçok çalışma bulunmaktadır [3,5]. Ancak TEK yöntemi, talaşlı imalat yöntemi ile karşılaştırıldığında üretilen parça sayısı ve parça geometrisi karmaşıklığı arttıkça avantajlı bir konuma geçmektedir. Ayrıca parça geometrisi karmaşıklığ 1 arttıkça TEK yöntemin de üretim maliyeti azalmaktadır [6,7].

İç ve dış kısmı farklı malzemeden olması istenen parçaların üretiminde difüzyon kaynağı yaygın bir şekilde kullanılmaktadır. $\mathrm{Bu}$ yöntem ile farklı malzemelerden yekpare parçalar üretilebilmektedir. Difüzyon kaynağ1 birleşmelerinde sıcaklık, süre ve basınç temel faktörlerdir. Ayrıca yapılan çalışmalarda birleşmenin kalitesini arttırmak için ara katman kullanılması gerektiği tespit edilmiştir [8].

Aust ve arkadaşları [9], TiAl6Nb7'den karmaşık geometrili bir kemik vida implantının imalatına yönelik çalışma yapmışlardır. TEK yöntemi ile hazırlanan parçaya mikro yapısal analizler ve mekanik testler yapmışlardır. Elde edilen sonuçlara göre bir kemik vidası implantının enjeksiyon kalıplama ve sinterleme parametreleri optimize edilmiştir. Çalışma sonucunda, kemik vidası implantının çekme mukavemetini, akma dayanımını, plastik uzama ve burulmaya karşı direnç değerlerini tespit etmişlerdir.

Meng ve arkadaşları [10] toz enjeksiyon kalıplama ile alüminadan mikro kanallı parçanın imal edilmesi ile ilgili çalışma yapmışlardır. Hammaddenin termal ve reolojik özelliklerini incelenmişlerdir. Kalıplama işleminden sonra mikro kanallı parçaları farklı sıcaklıklarda ve vakum ortamında sinterlemişlerdir. Kalıplama, bağlayıcı giderme ve sinterleme aşamalarının her birinin ardından yaptıkları incelemelerde mikro 
kanallı parçalarda herhangi bir çarpılma, eksiklik ve çatlama tespit etmemişlerdir.

Bianchi ve arkadaşları [11] çalışmalarında geleneksel enjeksiyon kalıplama yöntemine benzer bir şekilde seramik matriksli kompozit malzemeden rod üretmişlerdir. Çalışmalarında ergimiş hammaddeyi basınç ile kalıp içerisinde sıkıştırmışlardır. Çalışma sonucunda rodun mekanik özelliklerinde artış olduğunu belirlemişlerdir. Rodun vida profilinde de hedeflenen özellikleri elde edebilmişlerdir.

Joon ve arkadaşları [12] yaptıkları çalışmada toz enjeksiyon kalıplama yöntemi ile 316L paslanmaz çelik mikro ve nano tozlardan hazırlanmış besleme stoklarından numuneler üretmişlerdir. Deneyler sonucunda numunelerin yoğunluk ve tane büyüme davranışları ile birlikte mikro yapısal farklarını incelenmişlerdir. Nano tozların tane büyümesini azalttığını yoğunluğu ise arttırdığını belirlemişlerdir.

Urtekin ve arkadaşları [13] Ti-6Al-4V besleme stokundan kemik vida implantının imalatına yönelik çalışma yapmışlardır. Çalışmalarında kemik vida implatının üretilebilmesi için gerekli optimum kalıplama ve sinterleme parametrelerini tespit etmişlerdir.

Yılmaz ve arkadaşları [14] toz enjeksiyon kalıplama yöntemi ile küresel şekilli, hareketli ve kendinden montajlı parça üretimini araştırmışlardır. Parçayı oluşturan bileşenler arasındaki hareketin krom ara yüzey kullanarak elde edilebileceğini belirlemişlerdir.

Koçak ve arkadaşları [15] insörtlü toz enjeksiyon kalıplama yöntemi ile WC parça üretiminde ara katmanın etkisini incelemişlerdir. Deneyler sonucunda nikel ara katman ile kusursuz parça üretimini gerçekleştirebilmişlerdir.

Literatürde yapılan çalışmalarda yaygın olarak besleme stokunun hazırlandığı toz ve bağlayıcı maddelerin nihai parçanın mekanik özelliklerine etkisi üzerine odaklanılmıştır. TEK yöntemi ile hazırlanan parçanın içinde vida geometrisi elde edilmesi üzerine çok fazla çalışma bulunmamaktadır. Bu çalışmada maçalı kalıp kullanmadan iç kısmı vida geometrili parçanın üretilebilirliği araştırılmıştır. Ayrıca besleme stoku bölgesinin çekmesi (büzülmesi) ile insört üzerindeki vida geometrisinin kusursuz olarak elde edilmesi hedeflenmiştir. İlk olarak silindirik geometrili numuneler TEK yöntemi ile hazırlanmıştır. $\mathrm{Bu}$ numunelerin iç kısmına M4 kılavuz çekilmiştir. Vida profili elde edilmiş numunelerin içlerine diş profilinin bozulmaması için insörtler yerleştirilerek sinterleme deneyleri yapılmıştır. Parça içerisine yerleştirilen insörtler ile enjeksiyon bölgesi arasındaki difüzyonu önlemek için insörtler krom ve hegzagonal bor nitrür katmanları ile kaplanmıştır. Deneyler sonucunda insört ile besleme stoku bölgeleri arasındaki difüzyon engellenerek maça kullanmaksızın iç vida geometrisinin elde edilebilirliği araştırılmıştır.

\section{MATERYAL VE METOT}

\subsection{Materyal}

Sinterlenmiş parçaların iç kısmındaki vida geometrisinin elde edilmesi için insörtler kullanılmıştır. İnsört olarak AISI 1050 çeliğinden hazırlanmış krom kaplı M4 cıvata ve M4 saplama (Tij) kullanılmıştır (Şekil 1). AISI 1050 çeliğinin kimyasal özellikleri Çizelge 1'de verilmiştir. M4 saplamalar hegzagonal bor nitrür ile kaplanmıştır.

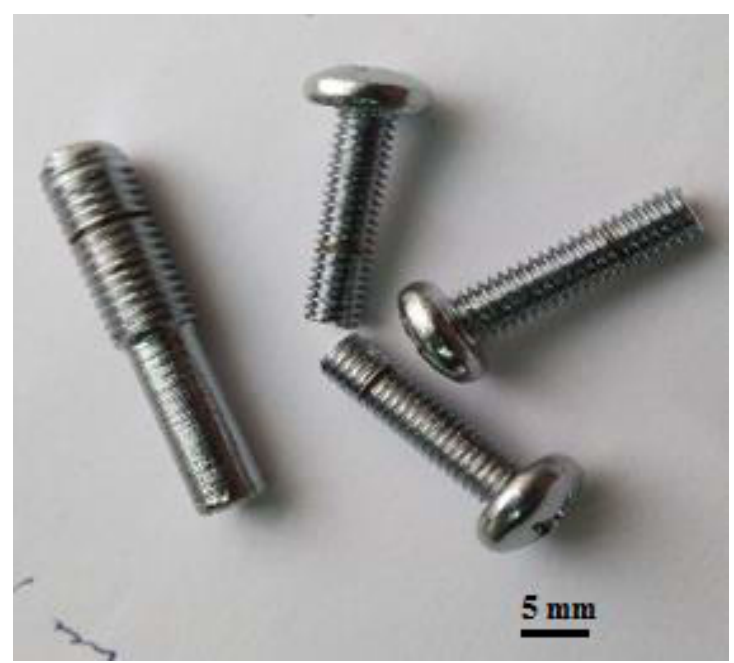

Şekil 1. M4 saplama ve cıvatalar 
Çizelge 1. AISI 1050 çeliğin kimyasal özellikleri

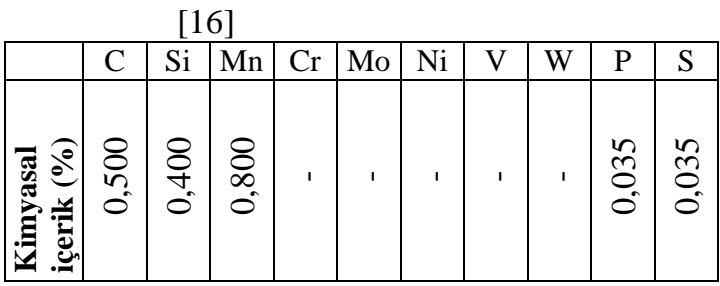

Deney numunelerinin hazırlanmasinda kullanilan 316L besleme stoku Almanya da bulunan eMBe (eMBe Products and Service GmbH, Thierhaupten, Germany) firmasından temin edilmiştir. Firma tarafından paylaşılan bilgiler çerçevesinde 316L besleme stokunun kimyasal bileşimi Çizelge 2'de, içindeki tozların özellikleri Çizelge 3'de verilmiştir.

Çizelge 2. $316 \mathrm{~L}$ besleme stokunun kimyasal özellikleri

\begin{tabular}{|c|c|c|c|c|c|c|c|}
\hline $\begin{array}{c}\mathrm{C} \\
(\%)\end{array}$ & $\begin{array}{c}\mathrm{P} \\
(\%)\end{array}$ & $\begin{array}{c}\mathrm{Cr} \\
(\%)\end{array}$ & $\begin{array}{c}\mathrm{Ni} \\
(\%)\end{array}$ & $\begin{array}{c}\mathrm{Mo} \\
(\%)\end{array}$ & $\begin{array}{c}\mathrm{Mn} \\
(\%)\end{array}$ & $\begin{array}{c}\mathrm{Si} \\
(\%)\end{array}$ & $\mathrm{Fe}$ \\
\hline 0,03 & 0,045 & $16-18$ & $12-15$ & $2-3$ & $<2$ & $\leq 1,0$ & $\begin{array}{c}\text { Geri } \\
\text { kalan }\end{array}$ \\
\hline
\end{tabular}

Çizelge 3. Besleme stokunda kullanılan tozun özellikleri

\begin{tabular}{|l|l|l|}
\hline $\begin{array}{l}\text { Üretim } \\
\text { yöntemi }\end{array}$ & Boyut & $\begin{array}{l}\text { Toz yükleme oranı } \\
\text { (ağırlıķa \%) }\end{array}$ \\
\hline $\begin{array}{l}\text { Su } \\
\text { atomizasyon }\end{array}$ & $\begin{array}{l}\mathrm{D}_{50}: 7 \mu \mathrm{m}, \\
\mathrm{D}_{90}: 13 \mu \mathrm{m}\end{array}$ & $\%$ 92,5-93,1 \\
\hline
\end{tabular}

\section{2. İnsörtlerde Kullanılan Ara Katmanlar}

Toz enjeksiyon kalıplama da insört üzerine besleme stoku enjekte edildiği zaman sinterleme sonrası insört ile besleme stoku bölgesi arasında bir difüzyon meydana gelmektedir. Bu çalışmada insört ile besleme stoku arasındaki difüzyonu engellemek için insörtler üzerinde bir ara yüzey oluşturulmuştur. İnsörtler üzerindeki ara yüzeyler krom ve hegzagonal bor nitrür ile elde edilmiştir. İnsörtler üzerindeki ara yüzeyler (krom ve hegzagonal bor nitrür) 5-7 $\mu \mathrm{m}$ kalınlığındadır. Krom arayüzey, sinterleme aşamasında difüzyonu engelleyici bir tabaka olarak işlev görmektedir. Kromun sinterleme aşamasında difüzyonu engelleyecek özellikleri bulunmaktadır (Çizelge 4).
Çizelge 4. Kromun difüzyon özellikleri [17-19]

\begin{tabular}{|c|c|c|}
\hline 0,166 & \multicolumn{2}{|l|}{ Atom yarıçapı (nm) } \\
\hline 1907 & \multicolumn{2}{|l|}{ Erime sicaklığ $1\left({ }^{\circ} \mathrm{C}\right)$} \\
\hline 547 & $\begin{array}{l}\text { Aktivasyon enerjisi } \\
(\mathrm{kj} / \mathrm{mol})\end{array}$ & \multirow{2}{*}{$\begin{array}{l}\text { Tungsten } \\
\text { içerisinde }\end{array}$} \\
\hline $10^{-10}$ & $\begin{array}{l}\text { Difüzyon katsayıs1 } \\
\left(\mathrm{cm}^{2} / \mathrm{s}\right)\end{array}$ & \\
\hline 291,8 & $\begin{array}{l}\text { Aktivasyon enerjisi } \\
(\mathrm{kj} / \mathrm{mol})\end{array}$ & \multirow{2}{*}{$\begin{array}{l}\text { Demir } \\
\text { içerisinde }\end{array}$} \\
\hline 10,8 & $\begin{array}{l}\text { Difüzyon katsayısı } \\
\left(\mathrm{cm}^{2} / \mathrm{s}\right)\end{array}$ & \\
\hline 70 & $\begin{array}{l}\text { Aktivasyon enerjisi } \\
(\mathrm{kj} / \mathrm{mol})\end{array}$ & \multirow{2}{*}{$\begin{array}{l}\text { Kobalt } \\
\text { içerisinde }\end{array}$} \\
\hline $7,3 \times 10^{-3}$ & $\begin{array}{l}\text { Difüzyon katsayısı } \\
\left(\mathrm{cm}^{2} / \mathrm{s}\right)\end{array}$ & \\
\hline
\end{tabular}

Hegzagonal bor nitrür (h-BN) fiziksel özellikleri ve kimyasal kararlılığı sebebiyle birçok uygulamada kullanılmaktadır. h-BN, bor ve azotun bir araya getirilmesiyle hazırlanan bir malzemedir. Bu malzeme, sıcaklık ve basınç etkisiyle kübik bor nitrüre dönüşür ve elmasın özelliklerini gösterir. Bor nitrür'ün tabakalar arası bağları zayıf olduğundan, düzensiz tabakalaşma çok kolay olur. Birbirine paralel veya dik yönde gelişi güzel dizilmiş olan bu tabakalar arasında boşluklar oluşur. Oluşan boşluklar ise, kullanım sırasında malzemenin ısıl şok direncini artırır [20-25].

Krom ve hegzagonal bor nitrürün bu özelliklerinden dolayı insörtler, bu malzemeler ile kaplanmış parçaya yerleştirilmiş, parça içerisindeki iç vida profilinin kalıpta maça kullanmadan oluşturabilmek için deneyler yapılmıştır.

\subsection{Toz Enjeksiyon Kalıplama, Bağlayıcı Giderme ve Sinterleme İşlemi}

Deney numuneleri toz enjeksiyon kalıplama tezgahında basıldıktan sonra bağlayıcı giderme ve sinterleme işlemlerine tabi tutulmuşlardır (Şekil 2). Toz enjeksiyon kalıplama parametreleri Çizelge 5'te verilmiştir. Bağlayıcı giderme işlemi $60{ }^{\circ} \mathrm{C}$ sicaklıkta etanol çözeltisinde 24 saat bekletilerek gerçekleştirilmiştir. Numunelerin sinterleme işlemi atmosfer kontrollü tüp fırın içerinde yapılmıştır. Numuneler $1260{ }^{\circ} \mathrm{C}-1340{ }^{\circ} \mathrm{C}$ 
sinterleme sicaklıklarında ve 30 ve 90 dakika sürelerde sinterlenmişlerdir. Sinterleme deneyleri $4,5{ }^{\circ} \mathrm{C} /$ dakika 1sitma hizında ve $95 \% \mathrm{~N}_{2}+5 \% \mathrm{H}_{2}$ karışım gaz atmosferinde yapılmıştır. Numunelerin soğutma hızı ise $5^{\circ} \mathrm{C} /$ dakika'dır.
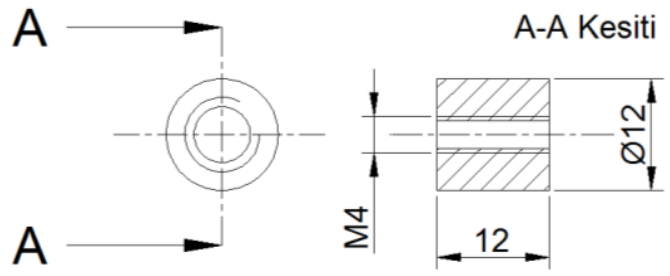

Şekil 2. Toz enjeksiyon kalıplamada hazırlanan numuneler

Çizelge 5. Toz enjeksiyon kalıplama parametreleri

\begin{tabular}{|c|l|}
\hline 1 & Enjeksiyon hızı $\left(\mathrm{cm}^{3} / \mathrm{s}\right)$ \\
\hline 120 & Enjeksiyon basıncı (bar) \\
\hline 3 & Enjeksiyon süresi (s) \\
\hline 50 & Ütüleme basıncı (bar) \\
\hline 150 & Enjeksiyon sıcaklığ $\left({ }^{\circ} \mathrm{C}\right)$ \\
\hline 45 & Kalı sıcaklığ $\left({ }^{\circ} \mathrm{C}\right)$ \\
\hline 5 & Soğutma süresi $(\mathrm{s})$ \\
\hline
\end{tabular}

\section{SONUÇLAR VE TARTIŞMA}

Çalışmada ilk olarak 316L besleme stokundan Çizelge 5 de belirtilen parametrelerde numuneler hazırlanmıștır. Kalıptan çıkan numunelere M4 kılavuz çekilmiştir (Şekil 3). Kılavuz çekilmiş numunelerin içerisine insörtler yerleştirilmiştir (Şekil 4). İnsörtler üzerinde krom ve hegzagonal bor nitrür kullanılarak ara yüzeyler oluşturulmuştur. Krom ara yüzeyin, diğer ara yüzey elementlerine göre (Nikel, bakır gibi) sinterleme aşamasındaki yüksek aktivasyon enerjisi $(547 \mathrm{kj} / \mathrm{mol})$, büyük atom çap $(0,332 \mathrm{~nm})$, yüksek difüzyon katsayısı $\left(10-10 \mathrm{~cm}^{2} / \mathrm{s}\right)$ ve yüksek erime sıcaklığı $\left(1907{ }^{\circ} \mathrm{C}\right)$ özellikleri sebebiyle [14] 316L besleme stoku ile AISI 1050 malzemesi arasındaki birleşmenin olmasını en aza indirmektedir. Hegzagonal bor nitrür ara yüzeyi ile de besleme stoku bölgesi ile insört arasındaki difüzyon ortadan kaldırılmak amaçlanmıştır.

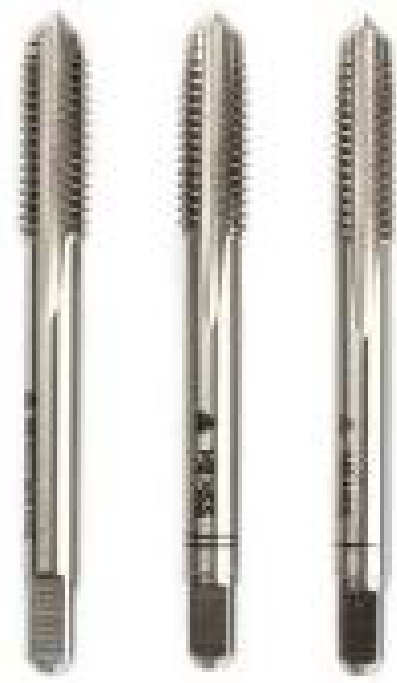

Şekil 3. M4 kılavuz takımı

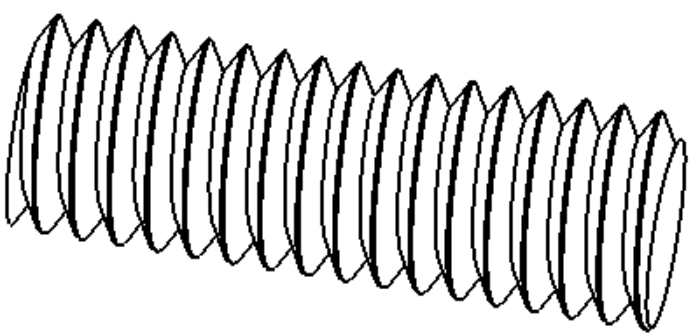

Şekil 4. İnsört (Ölçek 5/1)

İnsörtlü numuneler $1260 \quad{ }^{\circ} \mathrm{C}$ ve $1340 \quad{ }^{\circ} \mathrm{C}$ sicaklıklarda 30 ila 90 dakika sürelerde sinterlenmişlerdir (Şekil 5).

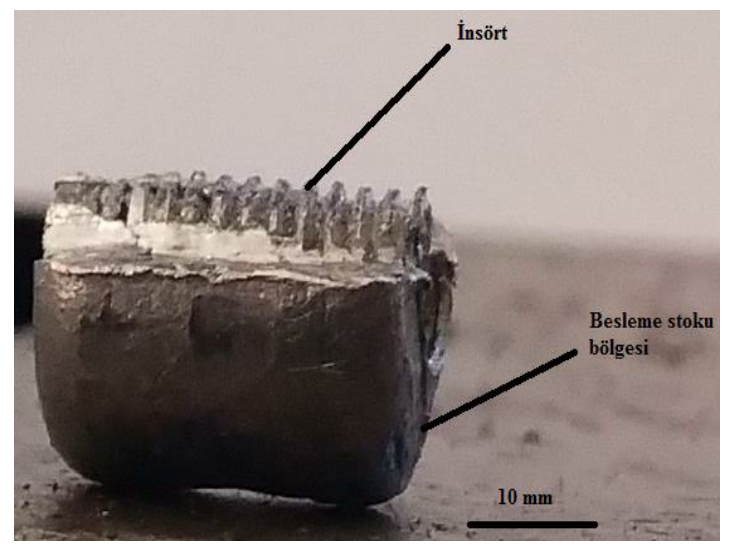

Şekil 5. $1340{ }^{\circ} \mathrm{C}$ sıcaklıkta sinterlenmiş numune 
İki farklı ara yüzey (krom ve hegzagonal bor nitrür) kullanılarak hazırlanan insörtlü numunelerde vida geometrisi elde edilememiştir. Deneyler sonucunda kullanılan ara katmanların insört ile besleme stoku bölgesi arasındaki difüzyonu engelleyemediği belirlenmiştir.

Sinterleme deneyleri sonrası numunelerin optik mikroskop görüntüleri çekilmiştir. Elde edilen görüntülerde bazı diş profillerinin sinterleme sonrası bozulduğu belirlenmiştir (Şekil 6).

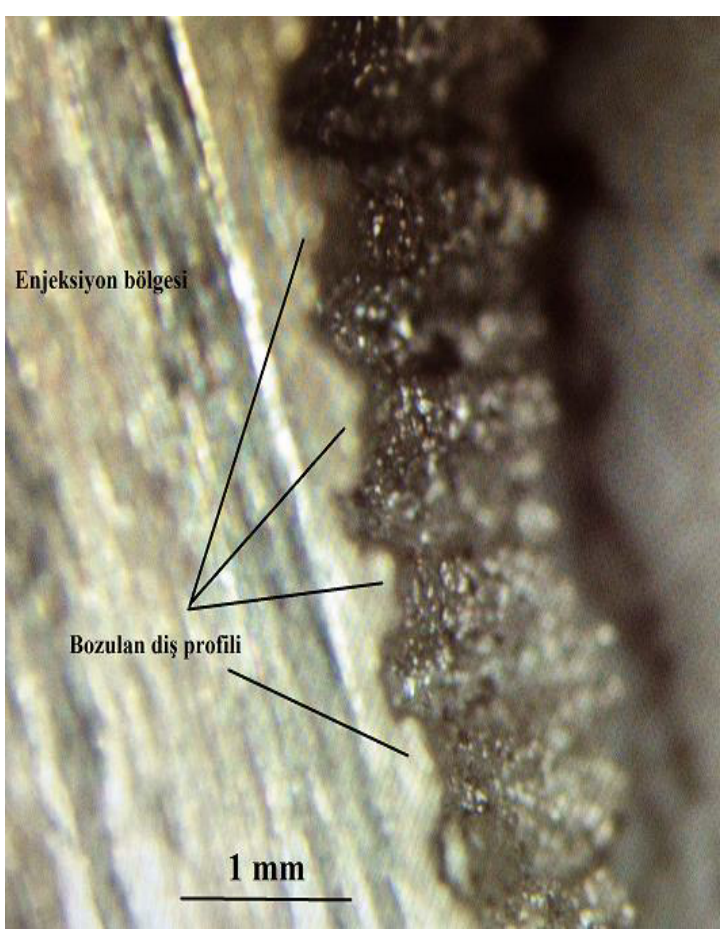

Şekil 6. Sinterlenmiş numunelerdeki bozulmuş diş profili

Numunelerdeki diş profilinin bozulmasının iki temel sebebi olduğu düşünülmektedir. Birinci sebebin numuneler kalıptan çıktıktan sonra ham malzemeler kılavuz çekme işlemine tabi tutulmuştur. $\mathrm{Bu}$ aşamada parçaların mukavemet değerleri oldukça düşüktür. Kılavuzların çekilmesi aşamasında dişlerde belirli bir miktar bozulma oluşabileceği düşünülmektedir. İkinci bir sebep ise insörtlerin numunelere takılması esnasında dişlerin profilinde bir bozulma oluşabileceği düşünülmektedir (Şekil 7).

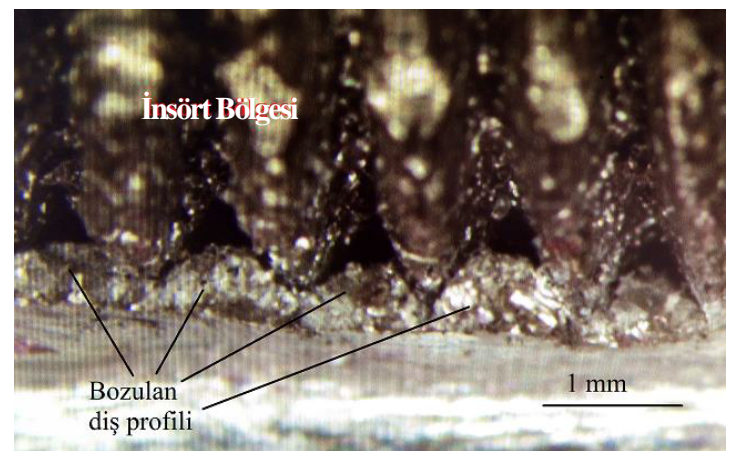

Şekil 7. İnsörtlü parçada bozulan diş profili

Numunelerde bozulan diș profili sayısı toplam diș sayısının yaklaşık \%20 ila \%30 kadardır. Bir diş profili bile bozulduğunda arada oluşturulan ara katman görevini tam olarak yerine getiremediği için besleme stoku bölgesi ile insört arasında bir difüzyon oluşmaktadır. Bu difüzyonda sinterleme sonrası insörtün parçadan uzaklaştırılmasını engellemektedir.

Aust ve arkadaşları [9] Ti6Al7Nb besleme stokundan, Urtekin ve Taşkın [13]'da Ti6Al4V besleme stokundan TEK yöntemi ile implantlarda kullanılan kemik vidasını başarılı bir şekilde üretebilmişlerdir. Fakat her iki çalışmada da vida profili parçanın dişında ve kalıp üzerindeki bir maça tarafından elde edilmiştir. Sinterleme işlemi sonrasında ise vida geometrilerinde herhangi bir değişiklik olmadığı belirtilmiştir. Bu çalışmada ise vida geometrisi parçanın iç kısmında elde edilmeye çalışılmıştır. Ayrıca iç vida geometrisinin elde edilmesi için maçalı bir kalıp tasarımı kullanılmamıştır.

Literatürde TEK yöntemi ile kendinden montajlı parçaların üretiminde sinterleme aşamasında koybolan ara katmanlar yaygın bir şekilde kullanılmaktadır [26-28]. Yılmaz ve arkadaşları [14] bu tekniğin maliyet ve zaman açısından kullanışlı olmadığını ortaya koyarak krom ara yüzeyini kullanmışlardır. Yaptıkları çalışmada küresel geometriye sahip parçalarda krom ara yüzeyinin aktivasyon enerjisi, atom çapı, difüzyon katsayısı ve erime sicaklığı değerlerinden dolayı parçanın kısımları arasında birleşmeyi engellediğini tespit etmişlerdir. Bu çalışmada da insört ile enjeksiyon bölgesi arasında birleşmeyi 
engellemek için krom ara yüzeyi kullanılmıştır. Fakat diş profillerindeki bozulmadan dolayı birleşmenin engellenemediği sonucuna ulaşılmıştır.

Bianchi ve arkadaşları [11] seramik matrisli kompozit malzemeden otomobil rotu üretimini araştırdıkları çalışmada diş geometrilerinin hedeflenen özellikte çıkması için bor nitrür kullanmışlardır. Diş geometrilerini bor nitrür ile kaplayarak kusursuz parça üretmeyi amaçlamışlardır. Yaptıkları çalışmada milin dış yüzeyinde vida geometrisi elde etmeye çalışmışlardır. Fakat çalışma sonucunda vida geometrilerinde bölgesel bozulmalar oluştuğunu belirlemişlerdir. Örneğin vida geometrisinin keskin kenarlarında eksilmeler tespit etmişlerdir. $\mathrm{Bu}$ çalışmada da elde edilmek istenen vida geometrinde bozulmalar olmuştur. Vida geometrilerindeki bozulmalardan dolayı ara katman ile elde edilmek istenen boşluk elde edilememiştir.

İnsörtlü toz enjeksiyon kalıplama yöntemi ile parça üretiminde, hacimsel çekmeden faydalanılmaktadır. Hacimsel çekme, insört üzerinde basınç oluşturularak difüzyonun sağlanmasına etki eder $[8,15]$. Ancak bu çalışmada ara bölgede boşluk elde edebilmek ve hacimsel çekmenin etkisini azaltmak için krom ve hegzagonal bor nitrür ara katmanlar kullanılarak difüzyon engellenmeye çalışılmıştır. Çalışmada hazırlanan numunelerin diş profillerinde bozulma olduğu optik görüntülerde belirlenmiştir. Diş profilindeki bozulmalar ara katmanın birleşmeyi engelleyici özelliğinin ortadan kaybolmasına sebep olduğu sonucuna ulaşılmıştır.

\section{SONUÇLAR}

İç ve dış kısmı farklı malzemelerden insörtlü toz enjeksiyon kalıplama yöntemi ile parça üretiminde malzemelerin hacimsel büzülmeleri önemli bir faktördür. İç ve dış kısım arasındaki hacimsel büzülme farkı difüzyonu pozitif yönde etkiler. Çalışmada besleme stoku bölgesi ile insört arasında boşluk elde edebilmek ve hacimsel büzülmenin etkisini azaltmak için krom ve hegzagonal bor nitrür ara katmanlar kullanılmıștır. Çalışmada insörtler üzerine uygulanan ara katmanların teorik olarak sinterlemede atomik geçiş gibi durumlara izin vermemesi ve bundan dolayı difüzyon oluşmasını engellemesi gerekmektedir. Fakat krom ve hegzagonal bor nitrür ara yüzeylerinin malzeme ve difüzyon karakterleri, boşluk oluşumu için yeterli olmamıştır. Ayrıca parçanın iç kısmında oluşturulan vida geometrilerinin bozulmasından dolayı ara katmanlar difüzyonun oluşumuna engel olamamıştır.

\section{TEŞEKKÜR}

$\mathrm{Bu}$ çalışma TUBİTAK (113M125) ve Gazi Üniversitesi BAP birimi (07/2013-03) tarafından desteklenmiştir.

\section{KAYNAKLAR}

1. Çakır, M.C., 2006. Modern Talaşlı İmalatın Esasları, Nobel Yayın Dağıtım, Ankara.

2. Uzun, G., 2013. Ti6Al4V Titanyum Alaşımında Kılavuz ile Vida Açma Problemlerinin Araştırılması, Doktora Tezi, Gazi Üniversitesi, Fen Bilimleri Enstitüsü, 110.

3. Şahinoğlu, A., Rafighi, M., 2020. Investigation of Vibration, Sound Intensity, Machine Current and Surface Roughness Values of AISI 4140 During Machining on The Lathe, Arabian Journal For Science And Engineering, 45(2), 765-778.

4. Şahinoğlu, A., Rafighi, M., 2020. Optimization of Cutting Parameters with Respect to Roughness for Machining of Hardened AISI 1040 Steel, Materials Testing, 62 (1), 85-95.

5. Ţalu, Ş., Kulesza, S., Bramowicz, M., Sağlam, H., Kus, R., 2020. Fractal Geometry of Internal Thread Surfaces Manufactured by Cutting Tap and Rolling Tap, Manufacturing Letters, 23, 34-38.

6. Karataş, Ç., Sarıtaş, S., 1998. Toz Enjeksiyon Kalıplama: Bir Yüksek Teknoloji İmalat Metodu, Gazi Üniversitesi Mühendislik Mimarlık Fakültesi Dergisi, 13(2), 193.

7. German, R.M., Bose, A., 1997. Injection Molding of Metals and Ceramics (First 
Edition). Metal Powder Industries Federation. New Jersey: Princeton, 5-280.

8. Koçak, H., Subaş1, M, Karataş, Ç., 2019. Sinter Bonding of AISI 4340 and WC-Co Using Ni Interlayer by Inserted Powder Injection Molding, Ceramics International, 45, 22331-22335.

9. Aust, E., Limberg, W., Gerling, R., Oger, B., Ebel, T., 2006. Advanced TiAl6Nb7 Bone Screw Implant Fabricated by Metal Injection Moulding, Advanced Engineering Materials, 8, 5, 365-370.

10. Meng, J., Ngiap, H.L., Gang, F., Bee, Y.T., Shu, B.T., 2011. Micro Powder Injection Moulding of Alumina Micro-Channel Part, Journal of the European Ceramic Society, 31, 1049-1056.

11. Bianchi, G., Vodermayer, A., Ortona, A., 2018. Net Shape CMC Components Produced by Composite Flow Moulding, Pyrolysis and Reactive Silicon Infiltration, Ceramics International, 44, 12204-12209.

12. Joon-Phil, C., Geon-Yong, L., Jun-Il, S., WonSik, L., Jai-Sung, L., 2015. Sintering Behavior of $316 \mathrm{~L}$ Stainless Steel Micro Nanopowder Compact Fabrical by Powder Injection Molding, Powder Technology, 279, 196-202.

13. Urtekin, L., Taskin, A., 2017. Ti-6Al-4V Alloy Cortical Bone Screw Production by Powder Injection Molding Method, Materials Express, 7(4), 245-252.

14. Yılmaz, O., Samet, K., Koçak, H., Karataş, Ç., 2019. Toz Enjeksiyon Kalıplamada Krom Arayüzeyi Kullanılarak Montajlı Parça İmalatının Araştırılması, Journal of the Faculty of Engineering and Architecture of Gazi University, 34(2), 621-634.

15. Koçak, H., Samet, K., Yılmaz, O., Karataş, Ç., 2018. Nikel Ara Katman Kullanılarak İnsörtlü Toz Enjeksiyon Kalıplama Yöntemiyle WCCo/HSS Kompozit Parça Üretiminin Araştırılması, GU J Sci, Part C, 6(2), 374-384.

16. Subaş1, M., Samet, K., Karataş, Ç., 2020. İnsörtlü Toz Enjeksiyon Kalıplamada İnsört Malzemesinin Araştırılması, GU J Sci, Part C, $8(2), 475-485$.

17. Sun, R., 1958. Diffusion of Cobalt and Chromium in Chromite Spinel, The Journal of Chemical Physics, 28(2), 290-293.
18. Gale, W.F., Totemeier, T.C., 2003. Smithells Metals Reference Book. ButterworthHeinemann.

19. Takasawa, K., Yamazaki, Y., Takaki, S., Abiko, K., Iijima, Y., 2002. Diffusion of $\mathrm{Cr}$ and $\mathrm{Fe}$ in a High-purity $\mathrm{Fe}-50$ Mass\% $\mathrm{Cr}-8$ Mass\% W Alloy, Materials Transactions, 43(2), 178-181.

20. Handan, A., 2018. Nanoyapıl1 Hegzagonal Bor Nitrür Üretimi ve Karakterizasyonu, Firat Üniv. Müh. Bil. Dergisi, 30(2), 269-275.

21. Pease, R.S., 1952. An X-ray Study of Boron Nitride, Acta Crystall, 5, 356- 361.

22. Dreissig, D.H., 2002. Synthesis of $B N$ Powders, Doktora tezi, Chemistry Dep. of The University of New Mexico, 295.

23. Materials Handbook for Refractories, 2002. Traditional \& Advanced Ceramics, Ceramic Industry, January, 26-136.

24. Gmelins Handbook of Inorganic Chemistry, 1988. Boron Compounds BN Special Issue, 8th edition, Springer Verlag, 1-89.

25. Lide, B.D.R., 1995. CRC Handbook of Chemistry and Physics, Student Edition, $76^{\text {th }}$ Edition, CRC Press, 1550.

26. Chartier, T., Delhomme, E., Baumard, J., Veltl, G., Ducloux, F., 2001. Injection Moulding of Hollow Silicon Nitride Parts Using Fusible Alloy Cores. Ceramics International - CERAM INT. 27, 821-827.

27. Attia, U., Hauata M., Walton I., Annicchiarico D. ve Alcock J., 2014. Creating Movable Interfaces by Micropowder Injection Moulding, Journal of Materials Processing Technology, 214(2), 295-303.

28. Williams, N., Whittaker, P., 2010. PM2010: Case Studies Highlight Global Success of Metal and Ceramic Injection Moulding. Powder Injectiong Moulding International, 4(4), 48-54. 